\title{
Downregulation of microRNA-181a attenuates hydrogen peroxide-induced human lens epithelial cell apoptosis in vitro
}

\author{
ZHAN SHI, YING SU, FENG WANG and PING LIU \\ Department of Ophthalmology, The First Affiliated Hospital, Harbin Medical University, \\ Harbin, Heilongjiang 150001, P.R. China
}

Received September 5, 2016; Accepted July 7, 2017

DOI: $10.3892 / \mathrm{mmr} .2018 .8608$

\begin{abstract}
Apoptosis of human lens epithelial (HLE) cells is a process closely associated with cataract formation. The aim of the present study was to explore the effects of microRNA (miR)-181a against hydrogen peroxide $\left(\mathrm{H}_{2} \mathrm{O}_{2}\right)$-induced apoptosis in HLE cells in vitro. The recombinant lentiviral plasmid pLKO. 1-puro-miR-181a was constructed and used to transfect human HLE-B3 cells with the short hairpin (sh)RNA to silence the expression of miR-181a. The apoptotic rate of both HLE-B3 cells in which miR-181a expression was stably silenced and in untransfected HLE-B3 cells was assessed in the presence of $\mathrm{H}_{2} \mathrm{O}_{2}$ using flow cytometry. The mRNA expression levels of the apoptosis-related genes caspase-3 (CASP3) and B-cell lymphoma-2-associated $\mathrm{X}$ protein $(B A X)$, and of the potential target genes for miR-181a, $c-M E T$, cyclooxygenase $2(C O X-2)$ and snail family transcriptional repressor 2 (SNAI2) were measured using reverse transcription-quantitative polymerase chain reaction (RT-qPCR). Malondialdehyde (MDA), superoxide dismutase (SOD) and catalase (CAT) levels were assessed using ELISA. RT-qPCR analysis revealed that miR-181a expression was downregulated in HLE-B3 cells following transfection with miR-181a-shRNA. Treatment with $\mathrm{H}_{2} \mathrm{O}_{2}$ significantly reduced the viability of HLE-B3 cells, whereas miR-181a knockdown was revealed to attenuate the effects on cell viability following $\mathrm{H}_{2} \mathrm{O}_{2}$ treatment. In addition, the downregulation of miR-181a expression significantly decreased $\mathrm{H}_{2} \mathrm{O}_{2}$-induced cell apoptosis, which was accompanied by a downregulation in $C A S P 3$ and $B A X$ and $C O X-2$ expression. Furthermore, the levels of MDA were decreased, whereas the levels of SOD and CAT were increased following miR-181a silencing. The present findings suggested that miR-181a knockdown may protect HLE-B3 cells against $\mathrm{H}_{2} \mathrm{O}_{2}$-induced apoptosis in vitro. The molecular mechanisms involved in
\end{abstract}

Correspondence to: Dr Ping Liu, Department of Ophthalmology, The First Affiliated Hospital, Harbin Medical University, 141 Yiman Road, Nangang, Harbin, Heilongjiang 150001, P.R. China E-mail: dao_zhan2000@126.com

Key words: cataract, lentivirus-based RNA interference, cell apoptosis, human lens epithelial cells, miRNA-181a the protective effects of miR-181a silencing may involve the suppression of $C A S P 3, B A X$ and $C O X-2$ expression, and the inhibition of MDA generation.

\section{Introduction}

Cataract is a major ophthalmological disorder that is characterized by the opacification of the eye lens (1). Cataract is an age-related disorder, and is one of the main causes of severe visual impairment or blindness in the aging population (2). Age-related cataract can lower the quality of life and affect the global economy, rendering the disease a significant public health issue (3). The causes of cataract are numerous and complex, and include drug-induced alterations, developmental abnormalities, ultraviolet radiation exposure, trauma and metabolic disorders (4). Previous studies have reported that the apoptosis of human lens epithelial (HLE) cells contributed to all types of cataract, with the exception of congenital disorders $(5,6)$. Furthermore, oxidative stress and the formation of oxygen free radicals are also involved in cataract, and have been identified as a major risk factor for cataract development $(4,7)$. Previous studies have demonstrated that hydrogen peroxide $\left(\mathrm{H}_{2} \mathrm{O}_{2}\right)$ could induce the apoptosis of HLE cells $(8,9)$; however, the molecular mechanisms implicated in $\mathrm{H}_{2} \mathrm{O}_{2}$-induced HLE cell apoptosis have yet to be fully elucidated.

MicroRNAs (miRNAs) have attracted attention in the efforts to elucidate the pathophysiological mechanisms implicated in various diseases or cancers (10). miRNAs are a class of small non-coding RNA molecules, 19-22 nucleotides long, which can target the 3 'untranslated region of mRNAs to induce translational repression or mRNA degradation (11). miRNAs have been reported to participate in the regulation of several physiological and pathological processes, including cell proliferation, apoptosis, senescence and stress response (12). Previous studies have suggested that the aberrant expression of miRNAs may be implicated in the pathogenesis of age-related diseases, including the progression of cataract $(3,13)$. One study reported that miRNA (miR)-125b was able to inhibit the apoptosis of HLE cells in age-related cataract by targeting p53 (14). Another study demonstrated that the let-7b miRNA precursor induced HLE cell apoptosis by directly regulating the expression of leucine-rich repeat-containing $G$ protein-coupled receptor 4 in cataract (15). However, the information available on miRNA expression in cataract-related tissues is limited. 
Previous studies have revealed that the downregulation of miR-181a was able to significantly inhibit the $\mathrm{H}_{2} \mathrm{O}_{2}$-induced apoptosis of cardiomyocytes (16), that miR-181a could inhibit the migration, proliferation and epithelial-mesenchymal transition (EMT) of lens epithelial cells (11). Therefore, it may be hypothesized that miR-181a serves a crucial role in the apoptosis of HLE cells induced by $\mathrm{H}_{2} \mathrm{O}_{2}$ and in the development of cataract in humans.

In the present study, RNA interference (RNAi) was performed using short hairpin (sh)RNA-based stable gene knockdown (17) to silence the expression of miR-181a in human HLE-B3 cells. The effects of miR-181a knockdown were evaluated on HLE-B3 proliferation and apoptosis in the presence of $\mathrm{H}_{2} \mathrm{O}_{2}$. In addition, the molecular mechanisms underlying the effects of miR-181a downregulation on HLE-B3 cell apoptosis were investigated. Elucidation of the functional roles of miR-181a may offer novel insight to decipher the complex regulatory mechanisms underlying the pathogenesis of cataract.

\section{Materials and methods}

Cell culture. Human HLE-B3 lens epithelial cells was were purchased from Jennio Biotech Co., Ltd. (Guangzhou, China) and the human 293T cell line was obtained from the Cell Bank of the Chinese Academy of Sciences (Shanghai, China). HLE-B3 and 293T cells were cultured in Dulbecco's modified Eagle's medium (DMEM) supplemented with $10 \%$ fetal bovine serum (FBS) and 1\% penicillin/streptomycin (all from both from Gibco; Thermo Fisher Scientific, Inc., Waltham, MA, USA). Cell cultures were maintained in a humidified incubator at $37^{\circ} \mathrm{C}$ in a $5 \% \mathrm{CO}_{2}$ atmosphere.

Generation of lentivirus-based RNAi plasmid. The hsa-miR-181a-5p sequence was obtained from the miRBase database (http://www.mirbase.org). The lentivirus-based RNAi transfer plasmid pLKO. 1-puro-miR-181a (miR-181a-shRNA) targeting miR-181a (5'-AACAUUCAACGCUGUCGG UGAGU-3') and the control plasmid pLKO. 1-puro were prepared using the pLKO. 1-puro plasmid obtained from the State Key Laboratory of Oncogenes and Related Genes, Shanghai Cancer Institute, Shanghai Jiao Tong University (Shanghai, China). To generate the pLKO. 1-puro-miR-181a, a miR-181a sponge was constructed using annealed oligonucleotides for tandem miR-181a-binding sites, as previously described (18). Briefly, the miR-181a sponge oligonucleotides (forward, 5'-CCGGACTCACCGACACGCATGAATGTT CCGGACTCACCGACACGCATGAATGTTCCGGACTCA CCGACACGCATGAATGTTTTTTTT-3' and reverse 5'-AAT TAAAAAAAACATTCATGCGTGTCGGTGAGTCCGGA ACATTCATGCGTGTCGGTGAGTCCGGAACATTCATG CGTGTCGGTGAGT-3') were annealed using 50 pmol forward and reverse oligonucleotides, and 10X polymerase chain reaction (PCR) buffer (Takara Bio, Inc., Otsu, Japan), and cloned after the U6 promoter in the AgeI/EcoRI-digested pLKO.1-puro vector for the construction of pLKO.1-puro-miR-181a. The annealing conditions were as follows: $94^{\circ} \mathrm{C}$ for $3 \mathrm{~min}$; followed by 55 cycles at $80^{\circ} \mathrm{C}$ for $30 \mathrm{sec}$ with $-1^{\circ} \mathrm{C} /$ cycle. The constructs were verified prior to use by sequencing by Sangon Biotech Co., Ltd. (Shanghai, China).
Lentiviral production. Lentivirus production and infection of the targeted cells were performed as previously described (19). Briefly, prior to transfection, $25 \times 10^{6} 293 \mathrm{~T}$ cells were plated onto $60 \times 15 \mathrm{~mm}$ Petri dishes and grown to $80 \%$ confluence. The cells were then co-transfected with $3 \mu \mathrm{g}$ psPAX2 packaging plasmid and $1 \mu \mathrm{g}$ pMD2.G envelope plasmid (both from Invitrogen; Thermo Fisher Scientific, Inc.), along with $4 \mu \mathrm{g}$ either pLKO.1-puro empty vector or pLKO.1-puro-miR-181a plasmid using Lipofectamine 2000 (Invitrogen; Thermo Fisher Scientific, Inc.) as the transfection reagent, according to the manufacturer's protocol. Cells were cultured in serum-free DMEM for $6 \mathrm{~h}$, following which the medium was replaced with DMEM supplemented with $10 \%$ FBS. The culture supernatants containing the lentiviral particles were collected at 48 and $72 \mathrm{~h}$ post-transfection. The supernatants were mixed, filtered by $0.45-\mu \mathrm{m}$ filter and concentrated by ultracentrifugation at $4,000 \mathrm{x} \mathrm{g}$ for $20 \mathrm{~min}$ at $4^{\circ} \mathrm{C}$. Viral supernatants were then aliquoted and stored at $-80^{\circ} \mathrm{C}$ as a viral stock.

Stable transduction with shRNA-encoding lentivirus. HLE-B3 cells were divided into the following 3 experimental groups: Normal control, negative control and shRNA-transfected groups. A total of $1 \times 10^{5}$ cells were seeded in complete DMEM medium in a 24 -well plate $24 \mathrm{~h}$ prior to transduction. Untreated HLE-B3 cells were used as the normal control group. The supernatant of the lentiviral particles containing the empty pLKO.1-puro vector was used to transduce the negative control cells for $24 \mathrm{~h}$ at $37^{\circ} \mathrm{C}$, followed by the addition of fresh complete DMEM medium, HLE-B3 cells were infected with the supernatant of the recombinant lentivirus containing the miR-181a-shRNA for $24 \mathrm{~h}$ at $37^{\circ} \mathrm{C}$, followed by the addition of fresh complete DMEM medium. Cells stably expressing the shRNA were obtained by puromycin selection at $\sim 72 \mathrm{~h}$ using DMEM containing $2 \mu \mathrm{g} / \mathrm{ml}$ puromycin until the HLE-B3 cells all died in the control group. Confirmation of miR-181a knockdown was performed by reverse transcription-quantitative PCR (RT-qPCR).

Cell proliferation assay. Cell proliferation was evaluated by the colorimetric water-soluble tetrazolium salt assay, Cell Counting Kit-8 (CCK-8; Dojindo Molecular Technologies, Inc., Kumamoto, Japan), according to the manufacturer's protocol immediately following confirmation of successful knockdown (20). Briefly, control or stably transfected HLE-B3 cells were seeded $\left(2 \times 10^{4}\right.$ cells/well) in 96-well round bottom plates immediately following transfection. Following overnight incubation at $37^{\circ} \mathrm{C}$ in serum-free medium, the cells were challenged with or without $200 \mu \mathrm{M} \mathrm{H}_{2} \mathrm{O}_{2}$ for $24 \mathrm{~h}$ at $37^{\circ} \mathrm{C}$. Subsequently, $10 \mu \mathrm{l}$ CCK-8 solution was added to each well and cells were incubated for another $4 \mathrm{~h}$ at $37^{\circ} \mathrm{C}$. The number of viable cells was assessed by measuring the optical density values of the samples at $450 \mathrm{~nm}$ using a microplate reader (Molecular Devices, LLC, Sunnyvale, CA, USA).

Flow cytometric analysis of apoptosis. Flow cytometry was used to assess cell apoptosis using an Annexin V-fluorescein isothiocyanate (FITC)/propidium iodide (PI) apoptosis detection kit (BD Biosciences, San Jose, CA, USA), according to the manufacturer's protocol. Briefly, control and stably trans-

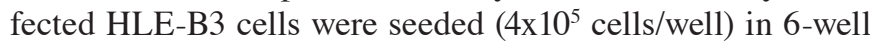


plates. Cells were cultured in serum-free medium overnight at $37^{\circ} \mathrm{C}$ and subsequently challenged with or without $200 \mu \mathrm{M}$ $\mathrm{H}_{2} \mathrm{O}_{2}$ for an additional $24 \mathrm{~h}$ at $37^{\circ} \mathrm{C}$. Cells were trypsinized, collected by centrifugation at $500 \mathrm{x}$ g at $4^{\circ} \mathrm{C}$ for $6 \mathrm{~min}$, washed with phosphate-buffered saline (PBS) and resuspended in $1 \mathrm{X}$ binding buffer. For apoptosis detection, $5 \mu \mathrm{l}$ annexin V-FITC and $5 \mu \mathrm{l}$ PI were added to a culture tube containing $100 \mu \mathrm{l}$ cell suspension and incubated for $15 \mathrm{~min}$ in a dark container at room temperature $\left(25^{\circ} \mathrm{C}\right)$. Subsequently, $400 \mu 1 \mathrm{X}$ binding buffer was added to each culture tube and the samples were assessed using a FACSCalibur flow cytometer with CellQuest software (version 5.1; BD Biosciences) within $1 \mathrm{~h}$. Apoptotic cell populations were detected by flow cytometric analysis and the fractions of cell population were analyzed in different quadrants through the quadrant statistics, with the results being calculated as percentages of apoptotic cells.

$R T$ - $q P C R$. Total RNA from normal and stably transfected HLE-B3 cells $\left(5 \times 10^{6}\right.$ cells), with or without $\mathrm{H}_{2} \mathrm{O}_{2}$ treatment, was isolated using TRIzol reagent (Invitrogen; Thermo Fisher Scientific, Inc.), according to the manufacturer's protocol. The purity and concentration of RNA were determined using a NanoDrop spectrophotometer (NanoDrop Technologies; Thermo Fisher Scientific, Inc., Wilmington, DE, USA) and an Agilent 2100 Bioanalyzer (Agilent Technologies, Inc., Santa Clara, CA, USA). RT-qPCR was performed to evaluate the expression of the apoptosis-related genes caspase-3 (CASP3) and B-cell lymphoma-2-assciated $\mathrm{X}$ protein $(B A X)$, and of the potential target genes for miR-181a $c-M E T$, cyclooxygenase 2 $(C O X-2)$ and snail family transcriptional repressor 2 (SNAI2). $\beta$-actin was used as the internal control to normalize gene expression levels. Sequences of the specific primers used in the present study are presented in Table I. All primers were designed and synthesized by Takara Biotechnology Co., Ltd. (Dalian, China).

First-strand cDNA was synthesized using the PrimeScript First-Strand cDNA Synthesis kit (Takara Biotechnology Co., Ltd.) with Oligo-dT primers in a $20 \mu \mathrm{l}$ reaction mixture containing $0.5 \mu \mathrm{g}$ DNase-treated RNA, $4 \mu \mathrm{l}$ 5X PrimeScript RT Master Mix and RNase-free water to a total volume of $20 \mu \mathrm{l}$, according to the manufacturer's protocol. The reaction was incubated at $37^{\circ} \mathrm{C}$ for $15 \mathrm{~min}$ and at $85^{\circ} \mathrm{C}$ for $5 \mathrm{sec}$. qPCR was performed on cDNA using Power SYBR Green PCR Master Mix in a 7500 Fast Real-Time PCR system (both from Applied Biosystems; Thermo Fisher Scientific, Inc.), according to the manufacturer's protocol. The PCR reaction volume was $20 \mu \mathrm{l}$, containing $10 \mu \mathrm{l} 2 \mathrm{X}$ SYBR Premix Ex Taq, $10 \mu \mathrm{M}$ of each primer, and diluted cDNA to a total volume of $20 \mu \mathrm{l}$. The thermocycling conditions were as follows: Initial denaturation at $50^{\circ} \mathrm{C}$ for $3 \mathrm{~min}$ and at $95^{\circ} \mathrm{C}$ for $30 \mathrm{~min}$, followed by 40 cycles at $95^{\circ} \mathrm{C}$ for $10 \mathrm{sec}$ and annealing at $60^{\circ} \mathrm{C}$ for $30 \mathrm{sec}$. The specificity was verified by melting curve analysis $\left(60-95^{\circ} \mathrm{C}\right)$ following the 40 cycles of amplification. Each sample was analyzed in triplicate. The quantification cycle $(\mathrm{Cq})$ was set within the exponential phase of the PCR and relative gene expression was calculated using the $2^{-\Delta \Delta \mathrm{Cq}}$ method (21).

For quantification of miRNAs, a TaqMan MicroRNA reverse transcription kit (Applied Biosystems; Thermo Fisher Scientific, Inc.) was used according to the manufacturer's protocol. The primers used for miR-181a were as follows:
Table I. Sequences of the primers used for reverse transcriptionquantitative polymerase chain reaction.

\begin{tabular}{ll}
\hline Gene & \multicolumn{1}{c}{ Primer sequence (5'-3') } \\
\hline FASP3 & F: GTGCTATTGTGAGGCGGTTGT \\
& R: TCCATGTATGATCTTTGGTTC \\
& F: AGAAGGCTAAAGGAAACGAA \\
& R: GGACCGTCAAGAAGTAAATAAA \\
COX-2 & F: CCCTGAGCATCTACGGTTTG \\
& R: CAGTATTAGCCTGCTTGTCT \\
FNAI2 & F: ATTTATGCAATAAGACCTATTCT \\
& R: AGGCTCACATATTCCTTGTCACA \\
$\beta$-actin & F: CTGACGGCAACTTCAACTGGG \\
& R: GGAGTCTCACCCAACCACCCT \\
& F: AGCGGGAAATCGTGCGTG \\
& R: CAGGGTACATGGTGGTGGTGCC
\end{tabular}

$B A X$, B-cell lymphoma-2-associated X protein; $C A S P 3$, caspase-3; COX, cyclooxygenase; F, forward; R, reverse; SNAI2, snail family transcriptional repressor 2 .

miR-181a forward, 5'-GCGGCGAACATTCAACGATG-3' and reverse, 5'-GTGCAGGGTCCGAGG-3'. Relative gene expression was calculated using the $2^{-\Delta \Delta \mathrm{Cq}}$ method (21).

Measurement of malondialdehyde (MDA), superoxide dismutase (SOD) and catalase (CAT) levels. Control and stably transfected HLE-B3 cells were seeded $\left(4 \times 10^{5}\right.$ cells/well) in 6-well plates. Cells were cultured in serum-free medium overnight at $37^{\circ} \mathrm{C}$ and subsequently challenged with $200 \mu \mathrm{M}$ $\mathrm{H}_{2} \mathrm{O}_{2}$ or with nothing for an additional $24 \mathrm{~h}$ at $37^{\circ} \mathrm{C}$. Cells were harvested and lysed by two rounds of sonication in $100 \mu \mathrm{l}$ PBS (3 times for $10 \mathrm{sec}$ ) in an ice-water bath, incubated at $-80^{\circ} \mathrm{C}$ for $30 \mathrm{~min}$ in between. Concentrations of MDA, SOD and CAT were measured using commercially available MDA ELISA kits (cat no. ml027131), SOD ELISA kit (cat no. ml026976), and CAT ELISA kit (cat no. ml026352) (all from Shanghai Enzyme-linked Biological Technology, Co., Ltd., Shanghai, China), according to the manufacturer's protocol. The absorbance of each sample was measured at $450 \mathrm{~nm}$ using a microplate reader (BioTek Instruments, Inc., Winooski, VT, USA).

Statistical analysis. All statistical analyses were performed using SPSS software version 17.0 (SPSS, Inc., Chicago, IL, USA). Data are expressed as the mean \pm standard deviation of 3 independent experiments. The statistical significance of the differences between groups was assessed using Student's t-test for pair-wise comparisons or one-way analysis of variance followed by the Student-Newman-Keuls post hoc test for multiple comparisons. $\mathrm{P}<0.05$ was considered to indicate a statistically significant difference.

\section{Results}

Lentiviral knockdown of miR-181a in HLE-B3 cells. Knockdown of miR-181a expression in HLE-B3 cells was 

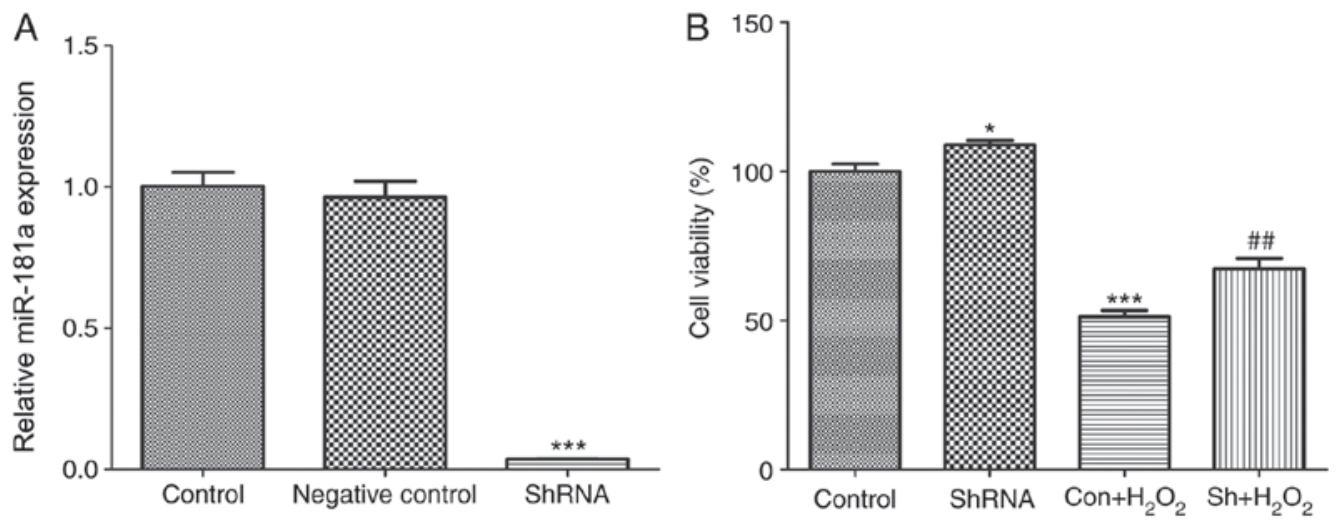

Figure 1. Effects of miR-181a silencing in HLE-B3 cells. (A) miR-181a expression levels in the normal control, the shRNA-negative control and the miR-181a-shRNA group. Data are expressed as the mean \pm standard deviation; ${ }^{* * * *} \mathrm{P}<0.001$ vs. control and negative control. (B) Effects of miR-181a knockdown with or without $\mathrm{H}_{2} \mathrm{O}_{2}$ co-treatment on the proliferation of HLE-B3 cells. Data are expressed as the mean \pm standard deviation; ${ }^{*} \mathrm{P}<0.05$ and ${ }^{* * * *} \mathrm{P}<0.001$ vs. con; ${ }^{\# \#} \mathrm{P}<0.01 \mathrm{Sh}+\mathrm{H}_{2} \mathrm{O}_{2}$ vs. con $+\mathrm{H}_{2} \mathrm{O}_{2}$. $\mathrm{H}_{2} \mathrm{O}_{2}$, hydrogen peroxide; con, control; HLE, human lens epithelial; miR, microRNA; sh, short hairpin RNA.
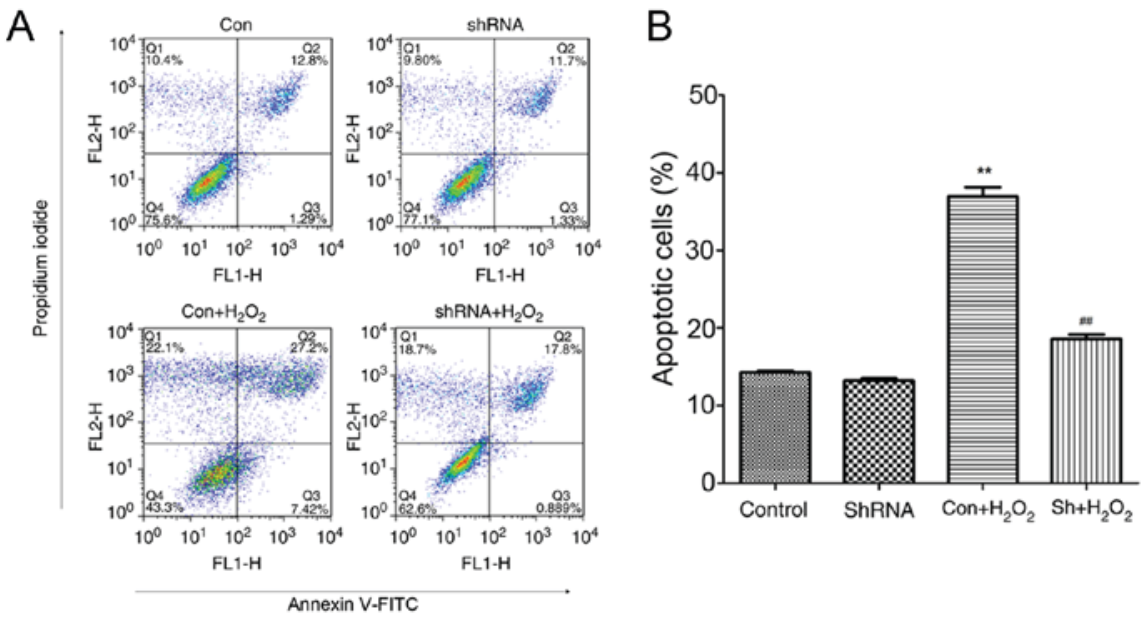

Figure 2. Analysis of HLE-B3 cell apoptosis. (A) HLE-B3 cell apoptosis was assessed using flow cytometry following staining with annexin V/FITC and PI. (B) Quantification of flow cytometry results. ${ }^{* *} \mathrm{P}<0.01$ vs. con, ${ }^{\# \#} \mathrm{P}<0.01$ vs. $\mathrm{Sh}+\mathrm{H}_{2} \mathrm{O}_{2}$ vs. con $+\mathrm{H}_{2} \mathrm{O}_{2}$. Con, control; FITC, fluorescein isothiocyanate; $\mathrm{H}_{2} \mathrm{O}_{2}$, hydrogen peroxide; HLE, human lens epithelial; miR, microRNA; PI, propidium iodide; shRNA, short hairpin RNA.

performed using pLKO.1-puro-miR-181a lentiviral particles that express a miR-181a-targeting shRNA, whereas an empty pLKO.1-puro vector was used as a negative control. To test the knockdown efficiency, the expression of miR-181a was examined using RT-qPCR $48 \mathrm{~h}$ post-infection. The expression levels of miR-181a in miR-181a-shRNA-transfected cells were significantly decreased compared with expression levels in the normal control and negative control cells $(\mathrm{P}<0.001$; Fig. $1 \mathrm{~A})$. These findings indicated that the construction of the HLE-B3 cell line in which miR-181a expression was stably silenced was successful.

miR-181a knockdown enhances HLE-B3 cell proliferation following $\mathrm{H}_{2} \mathrm{O}_{2}$ treatment. To assess the effects of shRNA-mediated miR-181a silencing on cell proliferation and survival following $\mathrm{H}_{2} \mathrm{O}_{2}$ treatment, the growth of HLE-B3 cells was investigated in vitro. miR-181a knockdown significantly enhanced the proliferation of HLE-B3 cells compared with normal control cells $(\mathrm{P}<0.05$; Fig. 1B). HLE-B3 cells treated with $\mathrm{H}_{2} \mathrm{O}_{2}(200 \mu \mathrm{M})$ exhibited a decrease in viability compared with untreated control cells ( $\mathrm{P}<0.001$; Fig. 1B). Notably, knockdown of miR-181a expression partially rescued $\mathrm{H}_{2} \mathrm{O}_{2}$-treated HLE-B3 cell viability, as compared with the untransfected $\mathrm{H}_{2} \mathrm{O}_{2}$-treated group $(\mathrm{P}<0.05$; Fig. $1 \mathrm{~B})$; however, the proliferation of shRNA-transfected $\mathrm{H}_{2} \mathrm{O}_{2}$-treated cells remained significantly reduced compared with the control group $(\mathrm{P}<0.01$; Fig. 1B). These findings suggested that shRNA-mediated miR-181a silencing may partially protect the viability of HLE-B3 cells against oxidative stress-induced compromise.

miR-181a knockdown counteracts $\mathrm{H}_{2} \mathrm{O}_{2}$-induced apoptosis in HLE-B3 cells. Decreased cell viability is closely associated with cell apoptosis (22); therefore, the present study examined whether the downregulation of miR-181a expression in HLE-B3 cells may exert a protective effect against $\mathrm{H}_{2} \mathrm{O}_{2}$-induced apoptosis. HLE-B3 cells infected with miR-181a-shRNA and treated with $\mathrm{H}_{2} \mathrm{O}_{2}$ appeared to be less susceptible to $\mathrm{H}_{2} \mathrm{O}_{2}$-induced damage, as indicated by the lower apoptotic rates compared with untransfected $\mathrm{H}_{2} \mathrm{O}_{2}$-treated cells $(\mathrm{P}<0.05$; Fig. 2$)$. However, no significant difference in the apoptotic rate was detected between the control and the shRNA-treated groups $(\mathrm{P}>0.05)$. These findings suggested that 

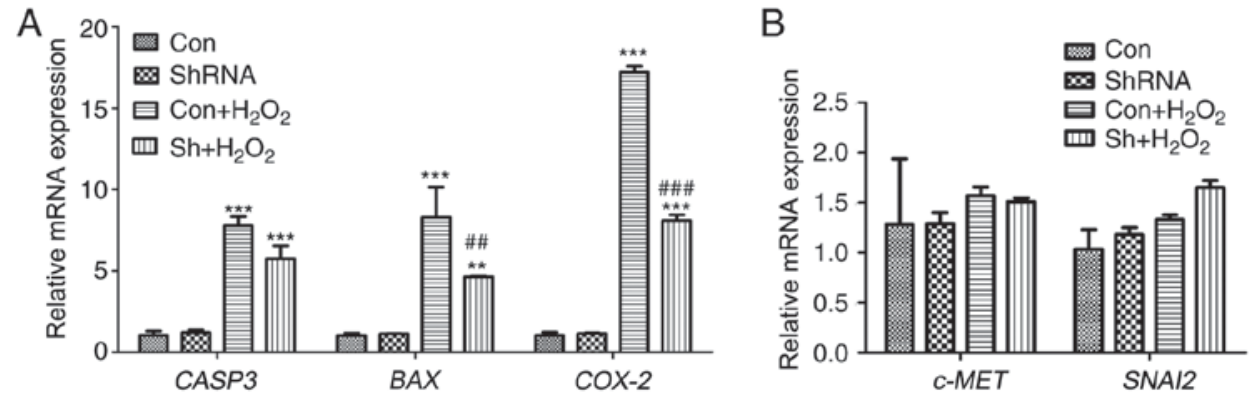

Figure 3. Alterations in gene expressions following miR-181a knockdown in HLE-B3 cells were assessed using reverse transcription-quantitative polymerase chain reaction. (A) Relative mRNA expression of the apoptosis-associated genes $C A S P 3$ and $B A X$, and of the potential miR-181a target gene $C O X-2$. (B) Relative mRNA expression of the potential miR-181a target genes $c-M E T$ and SNAI2. Data are expressed as the mean \pm standard deviation; ${ }^{* *} \mathrm{P}<0.01,{ }^{* * *} \mathrm{P}<0.001 \mathrm{vs}$. con; ${ }^{\# \#} \mathrm{P}<0.01,{ }^{\# \#} \mathrm{P}<0.001 \mathrm{Sh}+\mathrm{H}_{2} \mathrm{O}_{2}$ vs. con $+\mathrm{H}_{2} \mathrm{O}_{2}$. BAX, B-cell lymphoma-2-associated X protein; CASP3, caspase-3; con, control; COX-2, cyclooxygenase 2; $\mathrm{H}_{2} \mathrm{O}_{2}$, hydrogen peroxide; HLE, human lens epithelial; miR, microRNA; sh, short hairpin; SNAI2, snail family transcriptional repressor 2.
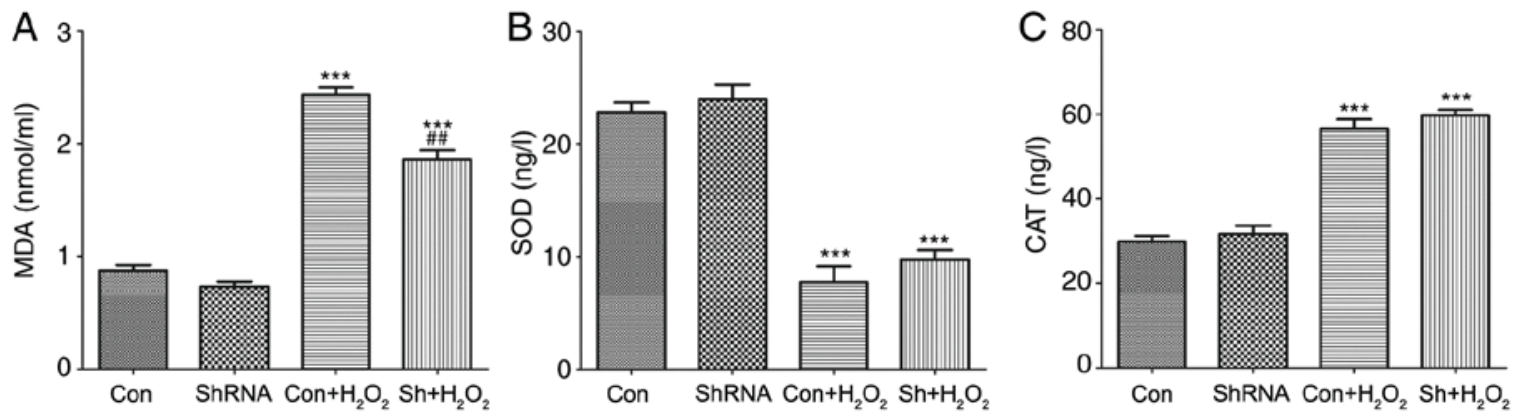

Figure 4. Levels of MDA, SOD and CAT were measured in HLE-B3 cells using ELISA kits. Intracellular expression levels of (A) MDA, (B) SOD and (C) CAT were measured in cells treated with or without miR-181a-shRNA and with or without $\mathrm{H}_{2} \mathrm{O}_{2}$ co-treatment. Data are expressed as the mean \pm standard deviation; ${ }^{* * * *} \mathrm{P}<0.001$ vs. con; ${ }^{\# /} \mathrm{P}<0.01$ vs. con $+\mathrm{H}_{2} \mathrm{O}_{2}$. CAT, catalase; con, control; $\mathrm{H}_{2} \mathrm{O}_{2}$, hydrogen peroxide; HLE, human lens epithelial; miR, microRNA; MDA, malondialdehyde; sh, short hairpin; SOD, superoxide dismutase.

the downregulation of miR-181a expression in HLE-B3 cells may exert a protective effect against $\mathrm{H}_{2} \mathrm{O}_{2}$-induced apoptosis.

Alterations in gene expression following miR-181a knockdown in HLE-B3 cells. To assess the potential effects of shRNA-mediated miR-181a silencing on gene expression, mRNA expression levels of the apoptosis-associated genes $C A S P 3$ and $B A X$, and of the potential target genes for miR-181a c-MET, COX-2 and SNAI2 were detected. The results demonstrated that there were no significant differences in shRNA vs. con without treatment. The present results demonstrated that $\mathrm{H}_{2} \mathrm{O}_{2}$ exposure significantly increased the expression of $C A S P 3, B A X$ and $C O X-2$ compared with expression levels in the normal control group $(\mathrm{P}<0.001 ;$ Fig. $3 \mathrm{~A})$. Notably, following knockdown of miR-181a expression in $\mathrm{H}_{2} \mathrm{O}_{2}$-treated cells, the mRNA expression levels of $B A X$ and $C O X-2$ were significantly suppressed compared with in untransfected $\mathrm{H}_{2} \mathrm{O}_{2}$-treated cells $(\mathrm{P}<0.01$ and $\mathrm{P}<0.001$ respectively; Fig. 3A). Conversely, cells treated with miR181a-shRNA with or without $\mathrm{H}_{2} \mathrm{O}_{2}$ co-treatment exhibited no significant effects on the mRNA expression levels of $c-M E T$ or SNAI2 ( $\mathrm{P}>0.05$; Fig. 3B). These results suggested that shRNA-mediated miR-181a silencing may affect the expression of apoptosis-associated genes CASP 3 and $B A X$, and of the putative $C O X-2$ miR-181a target gene.

Effects of miR-181a silencing on MDA, SOD and CAT expression levels. MDA is a product of lipid peroxidation and its intracellular levels are indicative of oxidative damage (14), whereas SOD and CAT are endogenous antioxidative enzymes (23). The levels of MDA, SOD and CAT in HLE-B3 cells from the various experimental groups are presented in Fig. 4. The results demonstrated that there were no significant differences in shRNA vs. con without treatment. The results demonstrated that in the presence of $\mathrm{H}_{2} \mathrm{O}_{2}$, the intracellular levels of MDA and CAT were significantly increased in HLE-B3 cells compared with expression in untreated control cells $(\mathrm{P}<0.001$; Fig. 4A and $\mathrm{C}$, respectively). Conversely, SOD expression levels were significantly reduced in cells following $\mathrm{H}_{2} \mathrm{O}_{2}$ treatment compared with untreated control cells $(\mathrm{P}<0.001$; Fig. 4B). Notably, the levels of MDA were significantly suppressed in $\mathrm{H}_{2} \mathrm{O}_{2}$-treated cells following miR-181a knockdown compared with in untransfected $\mathrm{H}_{2} \mathrm{O}_{2}$-treated cells $(\mathrm{P}<0.01$; Fig. 4A). Conversely, miR-181a-shRNA treatment exhibited no significant effects on the intracellular levels of SOD and CAT in the $\mathrm{H}_{2} \mathrm{O}_{2}$ co-treated group compared with the expression levels in the untransfected $\mathrm{H}_{2} \mathrm{O}_{2}$-treated cells ( $\mathrm{P}>0.05$; Fig. 4B and C, respectively). These results suggested that miR-181a knockdown may suppress the production of MDA following exposure to oxidative stress in vitro.

\section{Discussion}

Cataract is among the leading causes of blindness worldwide, and $90 \%$ of cataract-related cases of blindness occur in 
developing countries (4). miRNAs have garnered attention as a prominent class of gene expression regulators, and mounting evidence supports the implication of miRNAs in the pathophysiology of human cataract (12). The results of the present study suggested that the downregulation of miR-181a expression using RNAi-mediated suppression may protect or rescue HLE-B3 cells in vitro from undergoing apoptosis following $\mathrm{H}_{2} \mathrm{O}_{2}$ exposure. The molecular mechanisms underlying the effects of miR-181a knockdown in human lens cells may involve the suppression of $C A S P 3, C O X-2$ and $B A X$ expression, and the inhibition of MDA production.

Oxidative stress serves a crucial role in the regulation of several cellular events, including oxidative damage and cell death (24). Reactive oxygen species, including $\mathrm{H}_{2} \mathrm{O}_{2}$, may induce irreversible oxidative modifications to nucleic acids, lipids and proteins, and may lead to cellular damage and cell necrosis or apoptosis (25). A previous study observed a significant decrease in HLE-B3 cell viability in the presence of $200 \mu \mathrm{M} \mathrm{H}_{2} \mathrm{O}_{2}$ compared with control untreated cells (22); therefore. $200 \mu \mathrm{M} \mathrm{H}_{2} \mathrm{O}_{2}$ was used in the present study to treat HLE-B3 cells and to investigate the effects of silencing miR-181a expression. The present results demonstrated that following transduction with a lentiviral vector encoding miR-181a-shRNA, the expression of miR-181a was successfully silenced. Notably, miR-181a was revealed to partially rescue the compromise in HLE-B3 cell viability following oxidative stress exposure compared with viability in $\mathrm{H}_{2} \mathrm{O}_{2}$-treated cells.

Compromises in cell viability are closely associated to cell apoptosis, and the present study examined whether miR-181a downregulation in HLE-B3 cells following $\mathrm{H}_{2} \mathrm{O}_{2}$ exposure affected apoptotic signaling pathways. CASP3 mediates apoptosis thorough the regulation of several crucial events during apoptosis (26). During apoptosis, BAX proteins undergo conformational changes and translocate to the mitochondrial outer membrane, thus allowing the release of proapoptotic factors from the intermembrane space (27). A previous study reported that Grx2 was able to protect cells against $\mathrm{H}_{2} \mathrm{O}_{2}$-induced compromises in cell viability and against apoptosis through the inhibition of proapoptotic signaling, including BAX activation and CASP3 release (22). Similarly, the present results demonstrated that the downregulation of miR-181a suppressed the mRNA expression of $B A X$ and $C A S P 3$ in HLE-B3 cells. These results suggested that miR-181a may serve a significant role in the pathogenesis of cataract, through the regulation of $B A X$ and $C A S P 3$ expression in lens cells. Furthermore, the intracellular levels of MDA, SOD and CAT were investigated; MDA levels are indicative of oxidative damage (16), whereas SOD and CAT are antioxidative enzymes (23). The present results revealed that miR-181a knockdown suppressed the generation of MDA, thus suggesting that miR-181a silencing may inhibit oxidative damage associated with apoptosis in lens cells.

Several potential target genes have been identified for miR-181a: For example, a previous study demonstrated that miR-181a-5p was downregulated in hepatocellular cancer and suggested that miR-181a-5p may inhibit tumor motility and invasion by directly targeting the expression of $c$-Met (28). Another study suggested that miR-181a may suppress salivary adenoid cystic carcinoma metastasis by targeting the extracellular signal-regulated kinase/SNAI pathway (29). Furthermore,
miRNA-181a has been reported to inhibit the proliferation, migration and EMT of lens epithelial cells by directly targeting SNAI2 and COX-2 expression (11). Therefore, the present study investigated the expression of three potential target genes for miR-181a, namely $c-M E T, C O X-2$ and SNAI2 in HLE-B3 cells. The results demonstrated that miR-181a knockdown using RNAi significantly downregulated the mRNA expression of $\mathrm{COX}-2$ in $\mathrm{H}_{2} \mathrm{O}_{2}$-treated HLE-B3 cells compared with in untransfected $\mathrm{H}_{2} \mathrm{O}_{2}$-treated cells. However, $\mathrm{H}_{2} \mathrm{O}_{2}$ treatment and miR-181a silencing did not exert a significant effect on the mRNA expression levels of $c-M E T$ and SNAI2. The present data suggested that the downregulation of miR-181a expression may inhibit HLE cell apoptosis by targeting $C O X-2$ expression. Further studies are required to fully elucidate the molecular mechanisms and the target genes that are implicated in the protective effects of miR-181a knockdown.

In conclusion, the results of the present study suggested that the downregulation of miR-181a expression may protect or rescue HLE-B3 cells from undergoing apoptosis following $\mathrm{H}_{2} \mathrm{O}_{2}$ exposure in vitro. The molecular mechanisms underlying the protective effects of miR-181a silencing may involve the downregulation of $C A S P 3, B A X$ and $C O X-2$ expression, and the inhibition of lipid peroxidation. Further studies are required to fully elucidate the functional roles of miR-181a and may provide the foundation for a better understanding of the miRNA-mediated regulation of cataract development in the eye with eventual implications in the diagnosis and treatment of cataract.

\section{References}

1. Asbell PA, Dualan I, Mindel J, Brocks D, Ahmad M and Epstein S: Age-related cataract. Lancet 365: 599-609, 2005.

2. Hoffmann A, Huang Y, Suetsugu-Maki R, Ringelber CS, Tomlinson CR, Del Rio-Tsonis K and Tsonis PA: Implication of the miR-184 and miR-204 competitive RNA network in control of mouse secondary cataract. Mol Med 18: 528-538, 2012.

3. Khee SG, Yusof YA and Makpol S: Expression of senescence-associated microRNAs and target genes in cellular aging and modulation by tocotrienol-rich fraction. Oxid Med Cell Longev 2014: 725929, 2014

4. Chien KH, Chen SJ, Liu JH, Chang HM, Woung LC, Liang CM, Chen JT, Lin TJ, Chiou SH and Peng CH: Correlation between microRNA-34a levels and lens opacity severity in age-related cataracts. Eye (Lond) 27: 883-888, 2013.

5. Li WH, Kang ZF and Li L: Research of controlling genes of lens epithelial cell apoptosis and cataract. Int J Ophthalmol 10: 88-89 2010.

6. Li Y, Liu S, Zhang F, Jiang P, Wu X and Liang Y: Expression of the microRNAs hsa-miR-15a and hsa-miR-16-1 in lens epithelial cells of patients with age-related cataract. Int J Clin Exp Med 8: 2405-2410, 2014

7. Khan L, Khan RA, Ahmed W, Rauf A, Khan WM, Khan W, Durrani SA and Qayum: Frequency, causes and cutting-edge treatment of cataract: A review. American J Biomed Life Sci 3 . 25-28, 2015.

8. Yang Y, Sharma R, Cheng JZ, Saini MK, Ansari NH, Andley UP, Awasthi S and Awasthi YC: Protection of HLE B-3 cells against hydrogen peroxide-and naphthalene-induced lipid peroxidation and apoptosis by transfection with hGSTA1 and hGSTA2. Invest Ophthalmol Vis Sci 43: 434-445, 2002.

9. Bai J, Zheng Y, Dong L, Cai X, Wang G and Liu P: Inhibition of p38 mitogen-activated protein kinase phosphorylation decreases $\mathrm{H}_{2} \mathrm{O}_{2}$-induced apoptosis in human lens epithelial cells. Graefes Arch Clin Exp Ophthalmol 253: 1933-1940, 2015.

10. Tanaka Y, Tsuda S, Kunikata H, Sato J, Kokubun T, Yasuda M, Nishiguchi KM, Inada T and Nakazawa T: Profiles of extracellular miRNAs in the aqueous humor of glaucoma patients assessed with a microarray system. Sci Rep 4: 5089, 2014. 
11. Dong N, Xu B and Tang X: miRNA-181a inhibits the proliferation, migration and epithelial-mesenchymal transition of lens epithelial cells. Invest Ophthalmol Vis Sci 56: 993-1001, 2015.

12. Wu C, Lin H, Wang Q, Chen W, Luo H, Chen W and Zhang H: Discrepant expression of microRNAs in transparent and cataractous human lenses. Invest Ophthalmol Vis Sci 53: 3906-3912, 2012.

13. Peng CH, Liu JH, Woung LC, Lin TJ, Chiou SH, Tseng PC, Du WY, Cheng CK, Hu CC, Chien KH and Chen SJ: MicroRNAs and cataracts: Correlation among let-7 expression, age and the severity of lens opacity. Br J Ophthalmol 96: 747-751, 2012.

14. Yu Q, Zhao J, Min X, Wang M, Luo W, Wu D, Yan Q, Li J, Wu X and Zhang J: MicroRNA-125b inhibits lens epithelial cell apoptosis by targeting p53 in age-related cataract. Biochim Biophys Acta 1842: 2439-2447, 2014

15. Dong Y, Zheng Y, Xiao J, Zhu C and Zhao M: MicroRNA let-7b induces lens epithelial cell apoptosis by targeting leucine-rich repeat containing $\mathrm{G}$ protein-coupled receptor $4(\mathrm{Lgr} 4)$ in age-related cataract. Exp Eye Res 147: 98-104, 2016.

16. Wang L, Huang H, Fan Y, Kong B, Hu H, Hu K, Guo J, Mei Y and Liu WL: Effects of downregulation of microRNA-181a on $\mathrm{H}_{2} \mathrm{O}_{2}$-induced $\mathrm{H} 9 \mathrm{c} 2$ cell apoptosis via the mitochondrial apoptotic pathway. Oxid Med Cell Longev 2014: 960362, 2014.

17. Hu G and Luo J: A primer on using pooled shRNA libraries for functional genomic screens. Acta Biochim Biophys Sin (Shanghai) 44: 103-112, 2012.

18. Hatakeyama H, Murata M, Sato Y, Takahashi M, Minakawa N, Matsuda A and Harashima $\mathrm{H}$ : The systemic administration of an anti-miRNA oligonucleotide encapsulated $\mathrm{pH}$-sensitive liposome results in reduced level of hepatic microRNA-122 in mice. J Control Release 173: 43-50, 2014.

19. Stewart SA, Dykxhoorn DM, Palliser D, Mizuno H, Yu EY, An DS, Sabatini DM, Chen IS, Hahn WC, Sharp PA, et al: Lentivirus-delivered stable gene silencing by RNAi in primary cells. RNA 9: 493-501, 2003.
20. Zhang BG, Li JF, Yu BQ, Zhu ZG, Liu BY and Yan M: microRNA-21 promotes tumor proliferation and invasion in gastric cancer by targeting PTEN. Oncol Rep 27: 1019-1026, 2012.

21. Schmittgen TD and Livak KJ: Analyzing real-time PCR data by the comparative C(T) method. Nat Protoc 3: 1101-1108, 2008.

22. $\mathrm{Wu} \mathrm{H}$, Xing $\mathrm{K}$ and Lou MF: Glutaredoxin 2 prevents $\mathrm{H}_{2} \mathrm{O}_{2}$-induced cell apoptosis by protecting complex I activity in the mitochondria. Biochim Biophys Acta 1797: 1705-1715, 2010

23. Huang CK, Lin Y, Su H and Ye D: Forsythiaside protects against hydrogen peroxide-induced oxidative stress and apoptosis in PC12 cell. Neurochem Res 40: 27-35, 2015.

24. Bergamini CM, Gambetti S, Dondi A and Cervellati C: Oxygen, reactive oxygen species and tissue damage. Curr Pharm Des 10: $1611-1626,2004$

25. Giorgio M, Trinei M, Migliaccio E and Pelicci PG: Hydrogen peroxide: A metabolic by-product or a common mediator of ageing signals? Nat Rev Mol Cell Biol 8: 722-728, 2007.

26. Galluzzi L, López-Soto A, Kumar S and Kroemer G: Caspases connect cell-death signaling to organismal homeostasis. Immunity 44: 221-231, 2016.

27. Colin J, Garibal J, Clavier A, Szuplewski S, Risler Y, Milet C, Gaumer S, Guénal I and Mignotte B: Screening of suppressors of bax-induced cell death identifies glycerophosphate oxidase-1 as a mediator of debcl-induced apoptosis in drosophila. Genes Cancer 6: 241-253, 2015.

28. Korhan P, Erdal E and Atabey N: miR-181a-5p is downregulated in hepatocellular carcinoma and suppresses motility, invasion and branching-morphogenesis by directly targeting c-Met. Biochem Biophys Res Commun 450: 1304-1312, 2014

29. He Q, Zhou X, Li S, Jin Y, Chen Z, Chen D, Cai Y, Liu Z, Zhao T and Wang A: MicroRNA-181a suppresses salivary adenoid cystic carcinoma metastasis by targeting the MAPK-Snai2 pathway. Biochim Biophys Acta 1830: 5258-5266, 2013. 